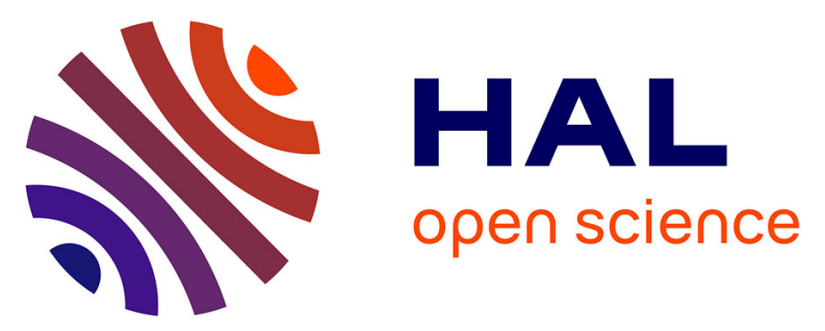

\title{
A comparative study of nine berberine salts in the solid state: optimization of the photoluminescence and self-association properties through the choice of the anion
}

Marine Soulié, Chantal Carayon, Nathalie Saffon, Sylvie Blanc, Suzanne Fery-Forgues

\section{To cite this version:}

Marine Soulié, Chantal Carayon, Nathalie Saffon, Sylvie Blanc, Suzanne Fery-Forgues. A comparative study of nine berberine salts in the solid state: optimization of the photoluminescence and selfassociation properties through the choice of the anion. Physical Chemistry Chemical Physics, 2016, 18 (43), pp.29999-30008. 10.1039/C6CP05848E . hal-02061656

\section{HAL Id: hal-02061656 https://hal.science/hal-02061656}

Submitted on 9 Nov 2021

HAL is a multi-disciplinary open access archive for the deposit and dissemination of scientific research documents, whether they are published or not. The documents may come from teaching and research institutions in France or abroad, or from public or private research centers.
L'archive ouverte pluridisciplinaire HAL, est destinée au dépôt et à la diffusion de documents scientifiques de niveau recherche, publiés ou non, émanant des établissements d'enseignement et de recherche français ou étrangers, des laboratoires publics ou privés. 


\section{Comparative Study of Nine Berberine Salts in the Solid State: Optimization of the Photoluminescence and Self-Association Properties through the Choice of the Anion}

Marine Soulié, ${ }^{\mathrm{a}}$ Chantal Carayon, ${ }^{\mathrm{b}}$ Nathalie Saffon, ${ }^{\mathrm{c}}$ Sylvie Blanc, ${ }^{\mathrm{d}}$ and Suzanne Fery-Forgues $\dagger^{\mathrm{b}}$

${ }^{a}$ CNRS-Université de Toulouse; ITAV-USR 3505; F31106 Toulouse, France

b SPCMIB, UMR5068, CNRS-Université Paul Sabatier-Toulouse III, 118 route de Narbonne, 31062 Toulouse cedex 9 , France

${ }^{c}$ Service commun RX, Institut de Chimie de Toulouse, ICT-FR2599, Université de Toulouse, F31062 Toulouse, France

${ }^{d}$ Université de Pau et des Pays de l'Adour; IPREM-UMR CNRS 5254; F64053 Pau cedex 9, France

† Corresponding author. E-mail: sff@chimie.ups-tlse.fr

Electronic Supplementary Information (ESI) available.

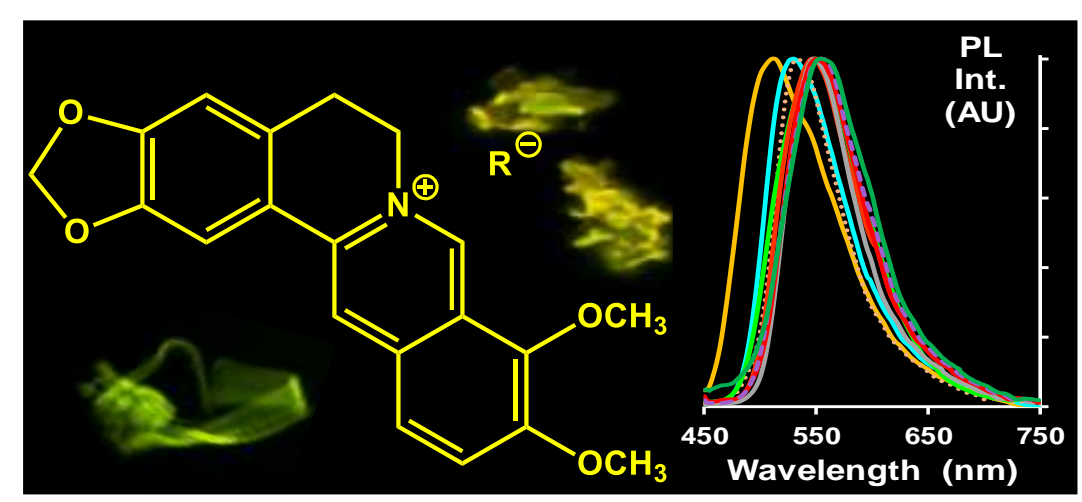

ABSTRACT: The arrangement of an ionic fluorophore in the crystalline state was regulated by the presence of various counter-ions and the effect upon spectroscopic and self-association properties was studied. To do so, nine salts of berberine (i.e. a fluorescent natural alkaloid) were investigated. Most of them contained organic anions and were prepared using an ion-exchange process. Berberine chloride and hemisulfate were also used for the sake of comparison. The diffuse reflectance and photoluminescence spectra were recorded on powder compounds. All salts were emissive in the solid state and the emission efficiency was increased seven fold with the nature of the anion. The optical properties were tentatively discussed on the basis of the crystal packing mode. The possibility of using a bottom-up approach to generate microparticles was investigated using the reprecipitation method. Salts that contain the most hydrophobic anions gave a large number of homogeneous, elongated microparticles. This study showed that most of the berberine salts could be used as fluorescent materials, but proper choice of the anion allows using the self-association properties to best advantage.

Keywords: fluorescent probes; crystal structure determination; photoluminescence; optical properties; nanofibers; reprecipitation. 


\section{INTRODUCTION}

Organic dye molecules that emit efficiently in the solid state are the key to many advanced applications in materials as well as in biological sciences, where they are of particular interest as micro- and nanoparticles. ${ }^{1-7}$ However, their development is challenging because the classic rules that allow designing efficient fluorophores for use in solution are not enough to ensure good solid-state emission properties. Not only should the molecules have a well-designed $\pi$-conjugated electron system, but they must also be properly arranged in the solid state. Otherwise, their emission is quenched upon aggregation, as is the case for the great majority of fluorophores. ${ }^{8-10}$ In the past decade, research efforts have concentrated on the identification of dyes usable for solid-state emission and the implementation of various strategies aimed mainly at preventing the very detrimental head-to-head stacking of fluorophores. ${ }^{11-13}$ Among these strategies, the concept of ion association is very promising. ${ }^{1-22}$ It consists in associating a charged fluorescent or potentially fluorescent dye with a spectroscopicallysilent organic counter-ion. Such a system has many advantages. The counter-ions govern the physical and photophysical properties of the salt obtained. Relatively bulky counter-ions play a prominent role in the molecular arrangement and may reduce dye stacking. In the best-case scenario, dyes that are not fluorescent in the solid state when associated with small inorganic counter-ions are fluorescent in the presence of large organic ions. As they are easily interchangeable, various counter-ions can be associated with the same dye, thus reducing the effort in synthesis and enhancing the potential of this dye for definite applications. Moreover, organic salts are strongly hydrophobic and are particularly well adapted to the preparation of micro- and nanoparticles in aqueous suspensions. The nature of the counter-ion thus influences the particle shape and size, as well as their biological behavior in the case of nanoparticles..$^{23,24}$

The bases of the concept being well established, it is now important to understand precisely how the counter-ions may control the optical properties. Despite the fact that many salts based on organic dyes are crystalline, very few systematic studies have made a correlation between molecular arrangement and optical properties. Following the example of the pioneering work of Hinoue et al. regarding anthracene-1,5-disulfonic acid amine salts, ${ }^{25}$ it seemed instructive to us to carry out a study using berberine salts.

Berberine is a natural alkaloid that has been used intensively in traditional Eastern medicines ${ }^{26}$ because of its wide biological and pharmacological activity. ${ }^{27-29}$ One of its advantages is the propensity to produce crystallized salts with a variety of anions. ${ }^{18,}$, 30-34 This delocalized cation also shows interesting photochemical and spectroscopic properties. ${ }^{35,}{ }^{36}$ It is a strongly-colored compound that can easily be monitored by UV-vis absorption spectroscopy. As a fluorophore, it is virtually not emissive in water, but its fluorescence is restored in lipid phases ${ }^{37,38}$ and constrained media. ${ }^{39,40}$ Some years ago, our team showed that berberine palmitate was emissive in the solid state and gave nanofibers using a plain method based on solvent exchange. ${ }^{18}$ Recently, the berberine cation was associated with three other organic anions. Solid-state emissive salts were also obtained and we observed that the nature of the counter-ion influenced the formation of nanoparticles as well as the uptake by living cells. ${ }^{23}$ Consequently, berberine salts seemed to be appropriate for the intended research.

The first purpose of the present work was therefore to examine in greater detail the solid-state spectroscopic properties of a large panel of berberine salts and to see if a correlation can be found with the molecular arrangement in the crystal. The second purpose was to gain an overview of the self- 
association properties by comparing the microparticles obtained using a reprecipitation method. To do so, we studied nine berberine salts differing by the nature of the anion (Figure 1).
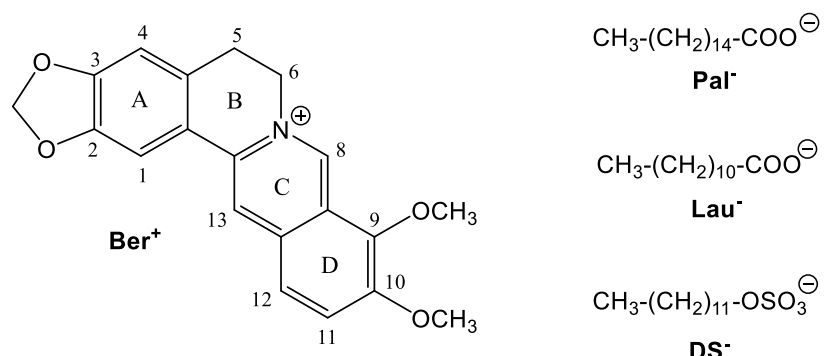

DS<smiles>CCCCC(CC)COC(=O)CC(C(=O)O[Na])C(=O)OCC(CC)CCCC</smiles>

$\mathrm{F}_{3} \mathrm{C}-\mathrm{SO}_{2}-\stackrel{\ominus}{\mathrm{N}}-\mathrm{SO}_{2}-\mathrm{CF}_{3}$

$\mathrm{NTf}_{2}{ }^{-}$
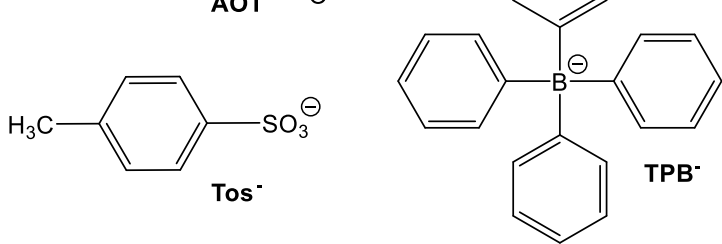

Figure 1. Chemical structures of the berberine cation $\left(\mathrm{Ber}^{+}\right)$and some associated anions: palmitate $\left(\mathrm{Pal}^{-}\right)$, laurate $\left(\mathrm{Lau}^{-}\right)$, dodecylsulfate $\left(\mathrm{DS}^{-}\right)$, dioctylsulfosuccinate $\left(\mathrm{AOT}^{-}\right)$, bis(trifluoromethane)sulfonimide $\left(\mathrm{NTf}_{2}^{-}\right), p$-tosylate $\left(\mathrm{Tos}^{-}\right)$and tetraphenylborate $\left(\mathrm{TPB}^{-}\right)$.

The four salts already used in our previous research work, i.e. palmitate $\left(\mathrm{Pal}^{-}\right)$, dioctylsulfosuccinate $\left(\mathrm{AOT}^{-}\right), p$-tosylate $\left(\mathrm{Tos}^{-}\right)$, and tetraphenylborate $\left(\mathrm{TPB}^{-}\right)$, were considered. Two new salts were prepared based on organic anions laurate $\left(\mathrm{Lau}^{-}\right)$and dodecylsulfate $\left(\mathrm{DS}^{-}\right)$. All these organic salts differed by their anionic groups and hydrophobic moieties that went from aliphatic to polyaromatic. The berberine cation was also associated with bis(trifluoromethane)sulfonimide $\left(\mathrm{NTf}_{2}^{-}\right)$. This type of very hydrophobic anion has been used to prepare solid state versions of ionic liquids that show interesting luminescence properties. ${ }^{20,41}$ Commercially available chloride and hemisulfate berberine salts were also used for the sake of comparison.

\section{RESULTS AND DISCUSSION}

\section{Synthesis and characterization of the berberine organic salts}

The berberine organic salts were obtained by mixing equimolecular amounts of berberine chloride $\left(\mathrm{Ber}^{+} \mathrm{Cl}^{-}\right)$and the desired anion as its alkaline salt, each compound being previously dissolved in hot distilled water. The organic salts thus formed readily precipitated. They were collected, rinsed with water to remove inorganic salts and dried under vacuum with gentle heating. The characterization was 
made by mass spectrometry (electrospray ionization technique, positive and negative modes) and ${ }^{1} \mathrm{H}$ NMR spectroscopy.

\section{Solid-state optical properties}

All the berberine salts studied in this work were bright yellow compounds. Dilute solutions were yellow and the UV-vis absorption spectra of the berberine cation typically exhibited four distinct bands between 200 and $500 \mathrm{~nm}$, including a weak long-wavelength band with maximum around $430 \mathrm{~nm}$ whatever the solvent. ${ }^{35}$ It was checked in acetonitrile that the nature of counter-ions hardly influenced the absorption properties in solution (Figure S1, Supplementary Information). Then, the reflectance spectra of the powder compounds were recorded (Figure 2). They all displayed a band in the blue region, with the maximum going up from $436 \mathrm{~nm}$ for $\mathrm{Ber}^{+} \mathrm{Tos}^{-}$to $457 \mathrm{~nm}$ for $\mathrm{Ber}^{+} \mathrm{Pal}^{-}$(all spectroscopic data were collected in Table 1). Absorption was therefore shifted to long wavelengths with respect to solutions. The shift magnitude and the broadness of the band depended on the nature of the counter-ion.

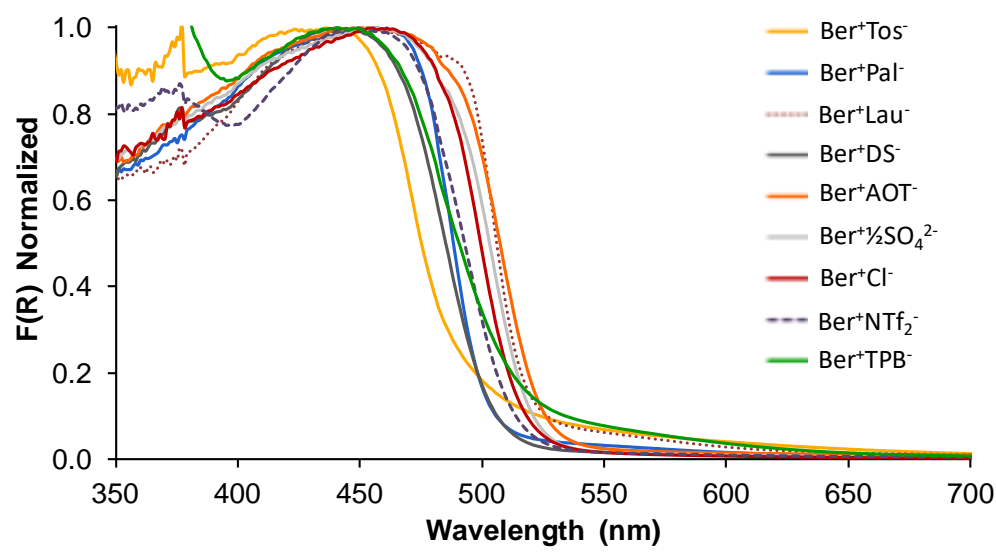

Figure 2. Normalized remission function of the UV-visible diffuse reflectance spectra of powder compounds.

\begin{tabular}{|l|l|l|l|}
\hline Compound & $\lambda_{\text {ref }}(\mathrm{nm})$ & $\lambda_{\text {em }}(\mathrm{nm})$ & $\Phi_{\mathrm{PL}}$ \\
\hline Ber $^{+} \mathrm{Tos}^{-}$ & 436 & $512^{a}$ & $0.031^{a}$ \\
\hline Ber $^{+} \mathrm{Pal}^{-}$ & 457 & $530^{b}$ & $0.044^{a}$ \\
\hline Ber $^{+} \mathrm{Lau}^{-}$ & 453 & 534 & 0.068 \\
\hline Ber $^{+} \mathrm{DS}^{-}$ & 440 & 548 & 0.073 \\
\hline Ber $^{+} \mathrm{AOT}^{-}$ & 450 & $546^{a}$ & $0.052^{a}$ \\
\hline $\mathrm{Ber}^{+} 1 / 2 \mathrm{SO}_{4}^{2-}$ & 453 & 548 & 0.070 \\
\hline $\mathrm{Ber}^{+} \mathrm{Cl}^{-}$ & 455 & 550 & 0.033 \\
\hline $\mathrm{Ber}^{+} \mathrm{TPB}^{-}$ & 441 & $552^{a}$ & 0.011 \\
\hline Ber $^{+} \mathrm{NTf}_{2}^{-}$ & 449 & 554 & 0.068 \\
\hline
\end{tabular}

Table 1. Diffuse reflectance maximum wavelengths $\left(\lambda_{\mathrm{ref}}\right)$, emission maximum wavelengths $\left(\lambda_{\mathrm{em}}\right)$ and photoluminescence quantum yields $\left(\Phi_{\mathrm{PL}}\right)$ of the berberine salts (microcrystalline powders). $\lambda_{\mathrm{ex}}=420 \mathrm{~nm} .{ }^{a}$ Data from ref. 23. ${ }^{b}$ Data from ref. 18. 
The emission properties of the berberine cation in dilute solution have been widely investigated in the literature. The fluorescence spectrum displays an unresolved band that peaks between $514 \mathrm{~nm}$ and $555 \mathrm{~nm}$ according to the solvent polarity. ${ }^{35}$ In contrast, very little is known about the solid-state properties. To our knowledge, only a preliminary study by our team has reported the solid-state properties of the four organic salts obtained with $\mathrm{Pal}^{-}, \mathrm{AOT}^{-}, \mathrm{Tos}^{-}$and $\mathrm{TPB}^{-} .{ }^{-23}$ This study was extended here to all berberine salts.

It was first checked that all the salts gave almost identical emission spectra in acetonitrile (Figure S2, Supplementary Information). This was obviously not the same in the solid state. All powder compounds were fluorescent when excited by a hand-held UV lamp, but emission showed varying degrees of intensity and ranged in color from greenish yellow to orange yellow depending on the counter-ion. The corresponding photoluminescence spectra were recorded using an integrating sphere. They showed an unresolved single band, with the maximum going up from $512 \mathrm{~nm}$ for Ber ${ }^{+}{ }^{-}$sos to 554 $\mathrm{nm}$ for $\mathrm{Ber}^{+} \mathrm{NTf}_{2}^{-}$(Figure 3). The position of the emission spectra thus strongly depended on the nature of the counter-ions. The wavelength shift observed with varying the counter-ion was comparable to that observed in solution with varying the solvent.

The photoluminescence quantum yields varied seven-fold with changing the counter-ion but remained in the same order of magnitude, in the $10^{-2}$ range. It can be noticed that new measurements were made on freshly prepared Ber ${ }^{+} \mathrm{TPB}^{-}$because an alteration of the sample color has been observed over time when the compound is not stored under rigorous conditions. By comparison with solutions, the emission quantum yield of the salts in the solid state was greater than or equal to that of the berberine

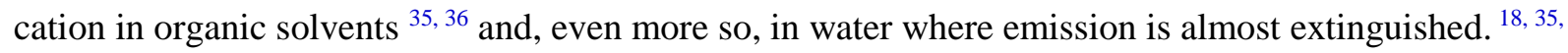
36

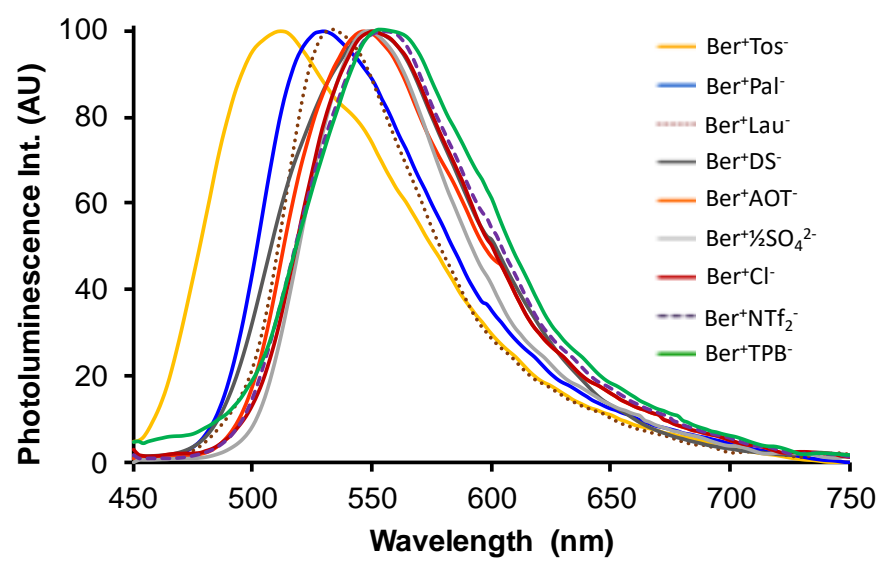

Figure 3. Photoluminescence spectra of the berberine salts (microcrystalline powders). $\lambda_{\mathrm{ex}}=420 \mathrm{~nm}$. All spectra were corrected and normalized.

\section{Crystallographic study}

It was checked by infrared spectroscopy that commercially available $\mathrm{Ber}^{+1} / 2 \mathrm{SO}_{4}{ }^{2-}$ and $\mathrm{Ber}^{+} \mathrm{Cl}^{-}$were hydrates (Figure S3, Supplementary Information). For Ber ${ }^{+1} / 2 \mathrm{SO}_{4}{ }^{2-}$, we relied on the structure of bis(berberine) sulfate heptahydrate reported by Kariuki and Jones. ${ }^{30}$ The structure was retrieved from the Cambridge Crystallographic Data Centre database (YUJJAO)..For $\mathrm{Ber}^{+} \mathrm{Cl}^{-}$, the manufacturer specifies that the water content is between 8 and $15 \%$. Most likely, commercially available $\mathrm{Ber}^{+} \mathrm{Cl}^{-}$is a 
mixture of dihydrate and tetrahydrate, the structure of which have both been reported in the literature. ${ }^{30 \text {, }}$ ${ }^{31}$ The crystal data of $\mathrm{Ber}^{+} \mathrm{Pal}^{-}$was reported by us in a previous study. ${ }^{18}$ Needles of Ber ${ }^{+} \mathrm{Lau}^{-}$were very slowly grown in water in a closed vessel. For all the other salts, monocrystals were obtained by slow evaporation of methanol solutions and the structures were analyzed by X-ray crystallography.

In the analysis of crystal structures, particular attention was paid to the interactions that take place between the most closely stacked fluorophores, because these interactions govern the solid-state spectroscopic behavior. The arrangement of stacked berberine cations together with a view of the crystal network were pictured in Figure 4. The berberine cations are not planar because of the twist induced by the ethane group of ring B (see Figure 1). In some cases, the overlapping moieties of the stacked cations were situated in different planes. For the delicate estimation of $\pi$ - $\pi$ overlap, a plane passing through the $\mathrm{C}$ and $\mathrm{D}$ rings of one cation was calculated and the projection of the stacked cation perpendicular to this plane was considered. The main characteristics of the various berberine salts are listed in Table 2. The general feature of these salts, with one exception, is that the cations were packed as antiparallel pairs.

In $\mathrm{Ber}^{+} \mathrm{TPB}^{-}$, the tetragonal geometry of the tetraphenylborate anion induced a particular packing mode where cations and anions were closely intricated. The cation pairs were roughly displayed according to two planes forming an angle of $68.4^{\circ}$ between them. In each pair, the $\pi$ - $\pi$ overlap was rather extended and the cations were quite distant from each other, seeing that they were separated by $3.6 \AA$. It is noteworthy that the torsion angle was only $3.6^{\circ}$, so that the cations were almost planar.

For the salts that contain small anions (i. e. Ber ${ }^{+} \mathrm{Tos}^{-}, \mathrm{Ber}^{+} \mathrm{NTf}_{2}^{-}, \mathrm{Ber}^{+} \mathrm{Cl}^{-}, \mathrm{Ber}^{+1} / 2 \mathrm{SO}_{4}{ }^{2-}$ ), the crystal structures were formed by berberine pillar units in which the berberine cations were stacked on each other. The $\pi-\pi$ overlap varied significantly according to the anion. The berberine pillars were separated by anions and possibly by solvent or water molecules. For instance, Ber ${ }^{+}{ }^{-}{ }^{-}{ }^{-}$crystallized with a molecule of methanol per unit cell. Each methanol molecule was linked to an oxygen atom of the tosylate anion by a hydrogen bond. The structure of $\mathrm{Ber}^{+} \mathrm{Cl}^{-} .4 \mathrm{H}_{2} \mathrm{O}{ }^{30}$ retrieved from the Cambridge database (YUJHAM) was given in Figure 4 as an illustration. The arrangement of the cations is very close in $\mathrm{Ber}^{+} \mathrm{Cl}^{-} \cdot 2 \mathrm{H}_{2} \mathrm{O}$. According to Tong et al., the main difference between the hydrates is that the packing of $\mathrm{Ber}^{+} \mathrm{Cl}^{-} .4 \mathrm{H}_{2} \mathrm{O}$ is less dense than that of $\mathrm{Ber}^{+} \mathrm{Cl}^{-} .2 \mathrm{H}_{2} \mathrm{O}$, because of the presence of more water molecules in the space between the berberine pillars. ${ }^{31}$ The molecules of water were linked by a network of hydrogen bonds, as it is also the case for $\mathrm{Ber}^{+1} / 2 \mathrm{SO}_{4}{ }^{2-}$. In $\mathrm{Ber}^{+} \mathrm{Cl}^{-} .4 \mathrm{H}_{2} \mathrm{O}$, one hydrogen bond took place between a water molecule and the methoxy group of the berberine cation.

For the salts that contain organic anions with fatty chains (i. e. Ber ${ }^{+} \mathrm{DS}^{-}, \mathrm{Ber}^{+} \mathrm{AOT}^{-}, \mathrm{Ber}^{+} \mathrm{Pal}^{-}$, $\mathrm{Ber}^{+} \mathrm{Lau}^{-}$), the most striking feature was that cations and anions formed distinct layers. Ber ${ }^{+} \mathrm{DS}^{-}$was the only salt in which cations displayed a columnar arrangement. The dodecylsulfate anions were arranged crosswise. Hydrogen bonds took place between one lattice water molecule and the sulfate groups of the anions. A columnar structure was not found for the other three salts. Each cation pair was slipped with respect to the next one, and so overlapping between the berberine structures belonging to two distinct pairs was small. Solving the structure of Ber ${ }^{+}$AOT $^{-}$was difficult because the alkyl chains of the AOT anion were disordered. The berberine cations showed extended overlap of the aromatic rings, and the interplanar distance was as short as 3.2 $\AA$. Regarding $\mathrm{Ber}^{+} \mathrm{Pal}^{-}$, the arrangement of cations was quite complex. In the dimers, the cations were arranged antiparallel, but stacked cations belonging to two different dimers were arranged parallel. The intermolecular distance between them was only $3.3 \AA$, indicating strong $\pi-\pi$ interaction. In Ber ${ }^{+} \mathrm{Lau}^{-}$, the berberine cations were displayed according to a herringbone structure. The angle between the planes was around $55.8^{\circ}$. It is noteworthy that $\mathrm{Ber}^{+} \mathrm{Lau}^{-}$is 
the only salt where stacked cations were oriented in the same direction. The overlap was small and the rings involved were not in parallel planes. Ber ${ }^{+} \mathrm{Lau}^{-}$crystal units contained four water molecules. Some water molecules were linked with the anion via $\mathrm{O}-\mathrm{H}---\mathrm{O}$ hydrogen bonds, and hydrogen bonding also occurred between lattice water molecules, forming a three-dimensional network structure.

\begin{tabular}{|c|c|c|c|c|}
\hline Compound & $\alpha\left(^{\circ}\right)$ & Orientation & $\pi-\pi$ Overlap & $D(\AA)$ \\
\hline $\mathrm{Ber}^{+} \mathrm{Tos}^{-}$ & 15.7 & anti-parallel & + & 3.4 \\
\hline $\mathrm{Ber}^{+} \mathrm{Pal}^{-}$ & 12.6 & $\begin{array}{l}\text { anti-parallel } \\
\text { parallel }\end{array}$ & $\begin{array}{l}++ \\
++\end{array}$ & $\begin{array}{l}3.5 \\
3.3\end{array}$ \\
\hline $\mathrm{Ber}^{+} \mathrm{Lau}^{-}$ & 14.0 & parallel & ++ & 3.3 \\
\hline Ber $^{+} \mathrm{DS}^{-}$ & 14.5 & anti-parallel & +++++ & 3.3 \\
\hline Ber $^{+}$AOT $^{-}$ & 15.3 & anti-parallel & ++++++ & 3.2 \\
\hline $\mathrm{Ber}^{+} 1 / 2 \mathrm{SO}_{4}^{2-}$ & 11.2 & anti-parallel & +++ & 3.4 \\
\hline $\mathrm{Ber}^{+} \mathrm{Cl}^{-}$ & 10.0 & anti-parallel & ++++ & 3.3 \\
\hline Ber $^{+} \mathrm{TPB}^{-}$ & 3.6 & anti-parallel & +++++ & 3.6 \\
\hline $\mathrm{Ber}^{+} \mathrm{NTf}_{2}^{-}$ & 17.5 & anti-parallel & ++++ & 3.6 \\
\hline
\end{tabular}

Table 2. Intramolecular torsion angle $(\alpha)$ of berberine cations and characteristics of two stacked berberine cations in the crystals: Relative orientation, $\pi-\pi$ overlap and shorter distance $(D) .{ }^{a}$ Data from ref. $18 .{ }^{b}$ Data from ref. 30. ${ }^{c}$ Average for two berberine cations in the unit cell.

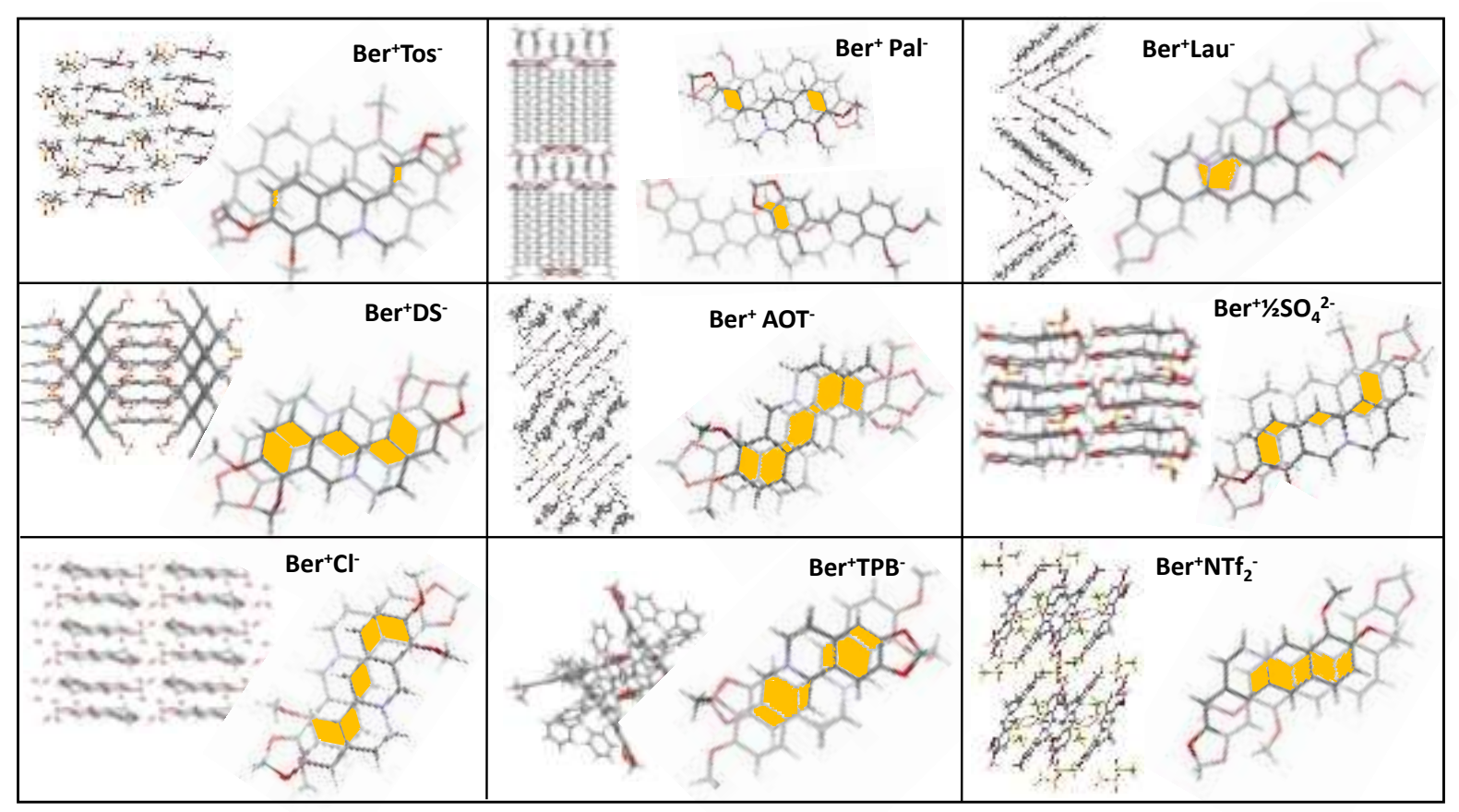

Figure 4. Crystal packing mode viewed along $a\left(\mathrm{Ber}^{+} \mathrm{AOT}-\mathrm{Ber}^{+} \mathrm{Lau}^{-}\right), b\left(\mathrm{Ber}^{+} \mathrm{Cl}^{-}\right)$and $c\left(\mathrm{Ber}^{+} \mathrm{Pal}^{-}, \mathrm{Ber}^{+} \mathrm{Tos}^{-}\right.$, $\left.\mathrm{Ber}^{+1} / 2 \mathrm{SO}_{4}{ }^{2-}, \mathrm{Ber}^{+} \mathrm{NTf}_{2}^{-}, \mathrm{Ber}^{+} \mathrm{DS}^{-}\right)$, and unit cell of Ber ${ }^{+} \mathrm{TPB}^{-}$. Arrangement of stacked berberine cations for the nine salts. The yellow color indicates the overlap of the aromatic systems. Structures of $\mathrm{Ber}^{+} \mathrm{Cl}^{-}$and $\mathrm{Ber}^{+1 / 2} \mathrm{SO}_{4}{ }^{2-}$ were from ref. 30, structure of $\mathrm{Ber}^{+} \mathrm{Pal}^{-}$was from ref. 18.

\section{Considerations on the link between the molecular arrangement and the spectroscopic properties}

The molecular arrangement of the berberine salts will now be discussed with respect to the spectroscopic data. Regarding the position of the solid-state reflectance and emission spectra, it was noticed that very 
small overlap (Ber+Tos ${ }^{-}$) is associated with spectra that are blue shifted with respect to the others. This feature is also found for emission for $\mathrm{Ber}^{+} \mathrm{Pal}^{-}$and $\mathrm{Ber}^{+} \mathrm{Lau}^{-}$, which combine reduced $\pi-\pi$ overlap with special arrangement of the cation pairs. In fact, the cations of $\mathrm{Ber}^{+} \mathrm{Lau}^{-}$were oriented parallel, and $\mathrm{Ber}^{+} \mathrm{Pal}^{-}$displayed a sort of intermediate packing mode with antiparallel and parallel-displayed cations. The excited state should therefore be less stabilized than in the other salts where cations are stacked antiparallel.

Contrary to our expectations, the photoluminescence quantum yield was not directly related to the $\pi-\pi$ overlap. Salts that present very small overlap (e.g. Ber' ${ }^{+}$os $^{-}$) could be expected to emit very efficiently, which was not the case, while other salts with extensive $\pi$ - $\pi$ overlap (e.g. Ber ${ }^{+} \mathrm{DS}^{-}$) were highly emissive. Similarly, parallel stacking is generally considered to be detrimental for photoluminescence, but the effect here seems to be weak because Ber ${ }^{+} \mathrm{Lau}^{-}$compared favorably with the most emissive berberine salts and $\mathrm{Ber}^{+} \mathrm{Pal}^{-}$was also relatively highly emissive. It could also be thought that excitons move more freely when the fluorophores are stacked in a columnar arrangement (e.g. $\mathrm{Ber}^{+} \mathrm{Cl}^{-}, \mathrm{Ber}^{+1} / 2 \mathrm{SO}_{4}^{2-}, \mathrm{Ber}^{+} \mathrm{NTf}_{2}{ }^{-}, \mathrm{Ber}^{+} \mathrm{Tos}^{-}$and $\mathrm{Ber}^{+} \mathrm{DS}^{-}$) than when they are slipped, and this leads to weaker emission. But again, this was not observed for most of these compounds. In summary, we have not found a satisfying correlation between solid-state emission efficiency and only one crystallographic parameter ( $\pi-\pi$ overlap, torsion angle, intermolecular distance, density of the crystal unit, etc.) that encompasses the whole set of compounds. The lack of simple correlation could be explained by the difficulty of photoluminescence quantum yield measurements. The absolute values remain relatively weak and small differences between the various salts may not be very accurate. Moreover, surface defects and impurities are also known to strongly influence photoluminescence efficiency and, most probably, different values would have been found using single crystals or powders prepared from recrystallization in other solvents or by mechanical milling. ${ }^{42}$ However, the photoluminescence quantum yield did vary sevenfold from one compound to another, and closely reflected differences between salts that were visible to the naked eye. It is most likely that the lack of simple correlation indicates that emission efficiency depends on various factors. Elaborate DFT calculations should be necessary to thoroughly understand the influence of all interactions upon the spectroscopic and photophysical properties.

However, some interesting features are emerging when comparing the compounds. It is noteworthy that the weaker torsion angle was found for the compound ( $\left.\mathrm{Ber}^{+} \mathrm{TPB}^{-}\right)$that was the less emissive in the solid state. Possibly, the constraints exerted on the cation influence the emission of light. Long-chained anions ( $\left.\mathrm{Pal}^{-}, \mathrm{Lau}^{-}, \mathrm{AOT}^{-}, \mathrm{DS}^{-}\right)$tend to form distinct layers. This type of arrangement is likely to be encountered when associating a large aromatic ion with a bulky aliphatic counter-ion. ${ }^{17,43}$ For our compounds, it is systematically associated with good photoluminescence. Our study shows that small variations of the alkyl chain length $\left(\mathrm{Ber}^{+} \mathrm{Lau}^{-} \mathrm{vs} \mathrm{Ber}^{+} \mathrm{Pal}{ }^{-}\right)$drastically modify the molecular arrangement in the crystal. The structuring linear alkyl chain of $\mathrm{Ber}^{+} \mathrm{Lau}^{-}$is also preferable to the branched chains of Ber $^{+}$AOT $^{-}$. Specific interactions with anions are likely to take place. If comparing salts that bear the same anionic group, the charge delocalization on the aromatic ring of $\mathrm{Ber}^{+} \mathrm{Tos}^{-}$brings no advantage with respect to high charge density $\left(\mathrm{Ber}^{+} \mathrm{AOT}^{-}\right)$. With the same chain length but a different anionic group, Ber ${ }^{+} \mathrm{Lau}^{-}$and $\mathrm{Ber}^{+} \mathrm{DS}^{-}$have different crystal packing modes, but photoluminescence is high in both cases. For organic compounds, the carboxylate, sulfate and sulfonate groups are thus equally suitable for photoluminescence. Finally, the hydrogen bonds formed between berberine cations and the lattice water molecules may play a prominent role in decreasing the emission efficiency. For instance, 
it was noticed that berberine chloride was much less emissive after recrystallization in water than the pristine material. The explanation is that recrystallization in water generated the tetrahydrate compound, while the commercial compound contains a large amount of dihydrate.

\section{Preparation of microparticles using the reprecipitation method}

With the exception of Ber ${ }^{+} \mathrm{TPB}^{-}$, which was weakly emissive, all the berberine salts studied above could be used as active compounds in photoluminescent materials, with relatively close optical properties. However, the nature of the anion may influence other properties, in particular the self-association properties, and this could be a decisive factor in choosing the right salt. Simple experiments provide a clear picture of how the compounds self-organize. This is the case for the reprecipitation method. In this solvent-exchange process, a concentrated solution of organic compound dissolved in a hydrophilic solvent is injected into a large volume of water. The organic compound precipitates in the aqueous medium due to the abrupt variation of its environment and may crystallize. The hydrophobicity of the organic compound is therefore of paramount importance. This is the reason why this value was estimated for the nine berberine salts before going any further. To do so, the log of the apparent octanol-water partition coefficient, $\log P_{a p p}$, was measured using a shake-flask procedure with detection by $\mathrm{UV}$-vis absorption spectroscopy. ${ }^{44,45}$ The measurement is not very rigorous because water was used instead of buffer to avoid any exchange of anions, and no correction was made. However, the $\log P_{a p p}$ values thus obtained allowed the compounds to be roughly compared (Table 3). As expected, the salts that contained inorganic $\left(\mathrm{Cl}^{-}, \mathrm{SO}_{4}{ }^{2-}\right)$ or small organic anions $\left(\mathrm{TPB}^{-}, \mathrm{Tos}^{-}\right)$were hydrophilic, while those containing $\mathrm{AOT}^{-}, \mathrm{DS}^{-}$and $\mathrm{NTf}_{2}^{-}$were clearly hydrophobic because the hydrophobicity of the anions compensates the hydrophilicity of the berberine cations. $\mathrm{Ber}^{+} \mathrm{Lau}^{-}$and $\mathrm{Ber}^{+} \mathrm{Pal}^{-}$were found to be more hydrophilic than expected, probably due to specific interactions of the carboxylate anion with water and to their surfactant properties. In fact, Ber ${ }^{+} \mathrm{Lau}^{-}$caused troublesome emulsions between octanol and water.

\begin{tabular}{|l|l|l|l|l|l|l|l|l|l|}
\hline Compounds & Ber $^{+}$Tos $^{-}$ & Ber $^{+} \mathrm{Cl}^{-}$ & Ber $^{+1} / 2 \mathrm{SO}_{4}{ }^{2-}$ & Ber $^{+} \mathrm{Pal}^{-}$ & Ber $^{+} \mathrm{Lau}^{-}$ & Ber $^{+} \mathrm{TPB}^{-}$ & $\mathrm{Ber}^{+} \mathrm{NTf}_{2}^{-}$ & Ber $^{+} \mathrm{DS}^{-}$ & Ber $^{+} \mathrm{AOT}^{-}$ \\
\hline $\log P_{a p p}$ & -1.03 & -0.93 & -0.67 & -0.61 & -0.45 & -0.21 & +0.19 & +1.73 & +1.91 \\
\hline
\end{tabular}

Table 3. Apparent octanol-water partition coefficient $\log P_{a p p}$ of the berberine salts, in increasing order.

Particles were then prepared. In a previous study, $\mathrm{Ber}^{+} \mathrm{Pal}^{-}$was found to form nanofibers spontaneously using the reprecipitation method. ${ }^{18}$ In the present work, this method was extended to the other eight salts of berberine. To do so, $25 \mu \mathrm{L}$ of a concentrated solution of the berberine salts at $5 \times 10^{-}$ ${ }^{3} \mathrm{M}$ in ethanol were rapidly injected in $2 \mathrm{~mL}$ deionized water, and the mixture was left in the dark at room temperature and stirred for 3 hours. The yellow mixture rapidly turned cloudy and fluorescent. The precipitate was more or less abundant according to the hydrophobicity of the salt.

The reprecipitation method is currently used for preparing aqueous suspensions of organic micro- and nanoparticles that can subsequently be separated by ultrafiltration, dried and introduced in materials. ${ }^{46}$ Here we chose to observe non-filtered suspensions at the end of the reprecipitation process, and to focus on particles that can be observed by fluorescence microscopy. It must be underlined that 
aqueous suspensions were observed between two glass slides, without any drying. At the concentration used, every salt gave suspensions of microparticles (Figure 5). Ber ${ }^{+} \mathrm{AOT}^{-}$yielded a large amount of flat, elongated microparticles with rounded tips that were about $15 \mu \mathrm{m}$ long and $2 \mu \mathrm{m}$ wide. These long microparticles were reminiscent of those found with $\mathrm{Ber}^{+} \mathrm{Pal}^{-}$, which were about $10 \mu \mathrm{m} \times 2 \mu \mathrm{m}$. Ber ${ }^{+} \mathrm{DS}^{-}$ led to thin fibers that could be very long (between 40 and $100 \mu \mathrm{m}$ ) and sometimes looked entangled. $\mathrm{Ber}^{+} \mathrm{Lau}^{-}$yielded a mixture of entwined ribbons and rod-like microcrystals. Heterogeneous populations of microparticles were concomitantly observed for $\mathrm{Ber}^{+} \mathrm{NTf}_{2}$, i.e. bunches of fibrils (each fibril being 2 to $5 \mu \mathrm{m}$ long), diamond-shaped microcrystals, and various particles between these two species. The particles formed by the other compounds were not as abundant. $\mathrm{Ber}^{+1 / 2} \mathrm{SO}_{4}{ }^{2-}$ generated both microcrystals and fibers, while only microcrystals were observed with $\mathrm{Ber}^{+} \mathrm{Cl}^{-}$. $\mathrm{Ber}^{+} \mathrm{Tos}^{-}$and $\mathrm{Ber}^{+} \mathrm{TPB}^{-}$yielded agglomerates of platelets and slightly elongated particles.

Under the experimental conditions used, the formation of elongated microparticles via the reprecipitation method was therefore observed for almost all the berberine salts. These particles were particularly abundant and regular for the most hydrophobic salts. They were particularly large for the berberine salts that contain bulky alkyl counter-ions. In contrast, hydrophilic salts gave rare and heterogeneous particles. The fact that elongated particles were found in almost every case, even in small amounts, suggests that the natural tendency of the berberine salts is to give this type of particles.
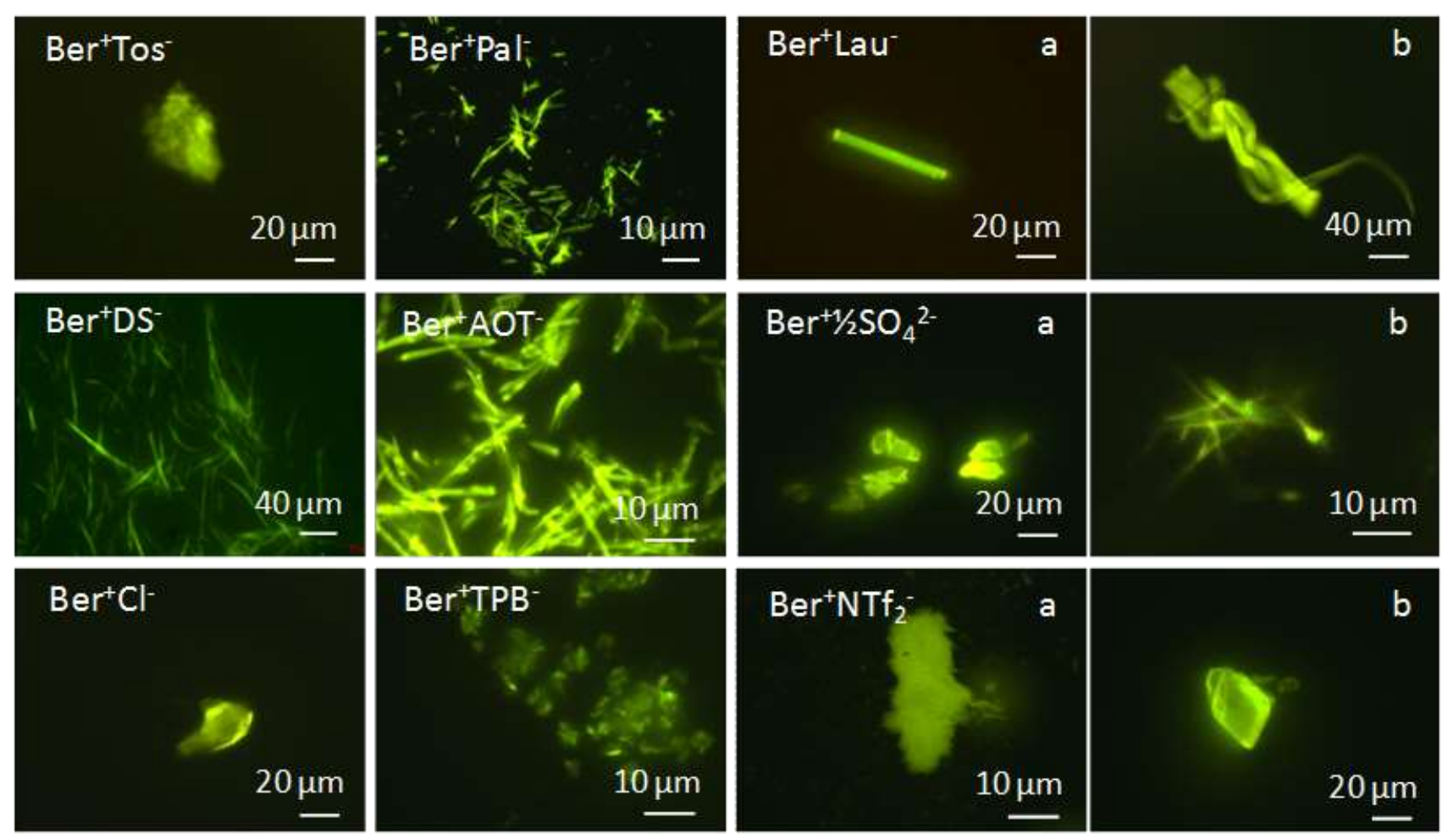

Figure 5. Fluorescence microscopy observation of the microparticles formed with the berberine salts after reprecipitation. Dye concentration in the mixture: $6.17 \times 10^{-5} \mathrm{M}$, ethanol in water $1.2 \%$. For Ber ${ }^{+} \mathrm{NTf}_{2}^{-}$, $\mathrm{Ber}^{+1 / 2} \mathrm{SO}_{4}{ }^{2-}$ and $\mathrm{Ber}^{+} \mathrm{Lau}^{-}, \mathrm{a}$ and $\mathrm{b}$ refer to two types of microparticles found in the same suspension.

According to the principles of crystal growth, fast-growing faces are the least developed. This means that only the small face that is perpendicular to the axis of maximum elongation has grown fast. 
Consequently, this face could then be similar in every compound, and probably related to the berberine cation. The polarity of the other faces should vary with the nature of the anion. It must also be kept in mind that the reprecipitation conditions are very far from equilibrium. The crystallization process is fast and the driving force is supersaturation. Since the formation of elongated microparticles is related to the salt hydrophobicity, it could simply result from high supersaturation.

This finding is particularly interesting because controlling the formation of fluorescent nanofibers is challenging, although remarkable attempts at rationalization have recently been made in this field. ${ }^{2}$ In fact, only a small number of organic molecules with low molecular weight spontaneously produce nanofibers. ${ }^{47,48}$ The formation of fibers is generally favored by the simultaneous presence of a large aromatic moiety and bulky alkyl chains, ${ }^{49}$ and the presence of additives is sometimes necessary. ${ }^{50}$ The present work shows that ion-exchange processes offer a new avenue for the preparation of elongated particles from aromatic molecules that are not covalently linked to a long alkyl chain.

\section{CONCLUSION}

Berberine salts allowed us to study the effect of counter-ions upon the spectroscopic and self-association properties of the same fluorophore. All the salts investigated were emissive in the solid state. Contrary to some spectacular cases reported in the literature, ${ }^{19,} 25$ the associated anions enabled modulation of the spectroscopic properties of berberine only to a certain extent. However, a clear conclusion is that it is advisable to use hydrophobic organic counter-ions to ensure good spectroscopic behavior. The nature of the anion affects the self-association properties to a greater extent. Here again, hydrophobic anions and in particular bulky alkyl anions reinforced the natural tendency of berberine to produce elongated particles that could be readily obtained by using a plain method such as the reprecipitation method. Preliminary results also indicated that experimental parameters of reprecipitation may be improved to get high-quality fibers of berberine, and drop casting was also used successfully, as will be published in two forthcoming papers. Methods that are easy to implement can thus be used to produce nanofibers in view of numerous applications, for example in new technology devices and in the field of fluorescent chemical and biochemical sensors. ${ }^{1-3}$ The same methods can be used to obtain small spherical particles and even nanoparticles, if desired for biological applications. ${ }^{4-6,22-24}$ In all these cases, the choice of the counter-ion plays a prominent role in making the most of one dye molecule with a minimum of synthesis.

\section{EXPERIMENTAL}

\section{Materials}

All compounds were used as received. Berberine (9,10-dimethoxy-2,3-methylenedioxy-5,6dihydrodibenzo $[a, g]$ quinolizinium) chloride, berberine hemisulfate, lauric acid and lithium bis(trifluoromethane)sulfonamide were purchased from Sigma Aldrich. Sodium dodecylsulfate was from Acros. Absolute ethanol (VWR and Sigma Aldrich) and high-pressure demineralized water (resistivity $18.3 \mathrm{M} \Omega . \mathrm{cm}$ ) prepared with a Milli-Q apparatus (Millipore) were used as solvents. 


\section{Synthesis of the berberine salts}

Berberine palmitate $\left(\mathrm{Ber}^{+} \mathrm{Pal}^{-}\right)$, dioctylsulfosuccinate $\left(\mathrm{Ber}^{+} \mathrm{AOT}^{-}\right)$, tosylate $\left(\mathrm{Ber}^{+} \mathrm{Tos}^{-}\right)$and tetraphenylborate $\left(\mathrm{Ber}^{+} \mathrm{TPB}^{-}\right)$were prepared as previously described. ${ }^{18,}{ }^{23}$ For the preparation of berberine dodecylsulfate $\left(\right.$ Ber $\left.^{+} \mathrm{DS}^{-}\right)$, berberine chloride $\left(100 \mathrm{mg}, 2.68 \times 10^{-4}\right.$ mole) was placed in $20 \mathrm{~mL}$ water, and sodium dodecylsulfate $\left(77.5 \mathrm{mg}, 2.68 \times 10^{-4}\right.$ mole) was dissolved in $20 \mathrm{~mL}$ water. Both solutions were gently heated until total dissolution of the salts. Upon mixing of the two hot solutions, a precipitate formed. After cooling down, it was separated by filtration on Büchner, thoroughly rinsed with water, and then dried under vacuum at $60^{\circ} \mathrm{C}$, yielding $133.7 \mathrm{mg}^{\circ} \mathrm{Ber}^{+} \mathrm{DS}^{-}$as a bright yellow powder. The same procedure was used to prepare berberine bis(trifluoromethane)sulfonamide $\left(\right.$ Ber $\left.^{+} \mathrm{NTf}_{2}{ }^{-}\right)$starting from $76.9 \mathrm{mg}\left(2.68 \times 10^{-4}\right.$ mole) of bis(trifluoromethane)sulfonamide lithium salt. A quantity of $113.6 \mathrm{mg} \mathrm{Ber}{ }^{+} \mathrm{NTf}_{2}^{-}$was obtained.

To prepare the berberine laurate salt, lauric acid $\left(53.8 \mathrm{mg}, 2.68 \times 10^{-4} \mathrm{~mole}\right)$ in $90 \mathrm{~mL}$ water was neutralized by $10.7 \mathrm{mg} \mathrm{NaOH}$ and heated to $40^{\circ} \mathrm{C}$. Mixing of this solution with an equimolar amount of $\mathrm{Ber}^{+} \mathrm{Cl}^{-}$in aqueous solution at $40^{\circ} \mathrm{C}$ induced the formation of a precipitate that first stuck to the bottom of the Erlenmeyer. After gentle stirring for one day at room temperature, small yellow needle-like crystals were obtained. They were filtered on Büchner and dried under vacuum at $60^{\circ} \mathrm{C}$, yielding 130 $\mathrm{mg}$ of Ber'Lau'.

Berberine dodecylsulfate $\left(\mathrm{Ber}^{+} \mathrm{DS}^{-}\right)$. Yield: $83 \% .{ }^{1} \mathrm{H}$ NMR $\left(\mathrm{CD}_{3} \mathrm{OD}\right): \delta \mathrm{ppm}=0.91(\mathrm{t}, J=6.0$ $\left.\mathrm{Hz}, 3 \mathrm{H}, \mathrm{CH}_{3}\right), 1.30\left(\mathrm{~m}, 18 \mathrm{H}, \mathrm{CH}_{2}\right), 1.66\left(\mathrm{~m}, J=6.0 \mathrm{~Hz}, 2 \mathrm{H}, \mathrm{C}_{2}-\mathrm{CH}_{2}-\mathrm{SO}_{4}{ }^{-}\right), 3.27$ (t, $J=6.0 \mathrm{~Hz}, 2 \mathrm{H}$, $\mathrm{H} 5), 3.99\left(\mathrm{t}, J=6.0 \mathrm{~Hz}, 2 \mathrm{H}, \mathrm{CH}_{2}-\mathrm{SO}_{4}{ }^{-}\right), 4.13\left(\mathrm{~s}, 3 \mathrm{H}, \mathrm{C} 10-\mathrm{OCH}_{3}\right), 4.23$ (s, 3H, C9-OCH $), 4.94$ (t, $J=$ $6.0 \mathrm{~Hz}, 2 \mathrm{H}, \mathrm{H} 6), 6.13$ (s, 2H, O-CH $2-\mathrm{O}), 6.98$ (s, 1H, H4), 7.68 (s, 1H, H1), 8.02 (d, J = 9.1 Hz, 1H, H12), $8.14(\mathrm{~d}, J=9.1 \mathrm{~Hz}, 1 \mathrm{H}, \mathrm{H} 11), 8.72(\mathrm{~s}, 1 \mathrm{H}, \mathrm{H} 13), 9.78$ (s, 1H, H8). Anal. calc. for $\mathrm{C}_{32} \mathrm{H}_{43} \mathrm{NO}_{8} \mathrm{~S} .1 / 2 \mathrm{H}_{2} \mathrm{O}: \mathrm{C}, 63.93 ; \mathrm{H}, 7.26 ; \mathrm{N}, 2.29$. Found: C, 63.48; H, 7.17; N, 2.59. ES-MS: $[\mathrm{M}]^{+}=336.3$; $[\mathrm{M}]^{-}=265.5$.

Berberine laurate $\left(\mathrm{Ber}^{+} \mathrm{Lau}^{-}\right)$. Yield: $85 \% .{ }^{1} \mathrm{H} \mathrm{NMR}\left(\mathrm{CD}_{3} \mathrm{OD}\right): \delta \mathrm{ppm}=0.91(\mathrm{t}, J=6.6 \mathrm{~Hz}, 3 \mathrm{H}$, $\left.\mathrm{CH}_{3}\right), 1.30\left(\mathrm{~m}, 16 \mathrm{H}, \mathrm{CH}_{2}\right), 1.60\left(\mathrm{~m}, J=7.5 \mathrm{~Hz}, 2 \mathrm{H}, \mathrm{C}_{2}-\mathrm{CH}_{2}-\mathrm{COO}^{-}\right), 2.16$ (t, $J=7.5 \mathrm{~Hz}, 2 \mathrm{H}, \mathrm{CH}_{2}-$ $\left.\mathrm{COO}^{-}\right), 3.27$ (t, $\left.J=6.4 \mathrm{~Hz}, 2 \mathrm{H}, \mathrm{H} 5\right), 4.13$ (s, 3H, C10-OCH $), 4.23$ (s, 3H, C9-OCH 3 ), 4.94 (t, $J=6.4$ $\mathrm{Hz}, 2 \mathrm{H}, \mathrm{H} 6), 6.13$ (s, 2H, O-CH ${ }_{2}-\mathrm{O}$ ), 6.98 (s, 1H, H4), 7.68 (s, 1H, H1), 8.02 (d, J = 9.1 Hz, 1H, H12), $8.15(\mathrm{~d}, J=9.1 \mathrm{~Hz}, 1 \mathrm{H}, \mathrm{H} 11), 8.73$ (s, $1 \mathrm{H}, \mathrm{H} 13), 9.79$ (s, $1 \mathrm{H}, \mathrm{H} 8)$. Anal. calc. for $\mathrm{C}_{32} \mathrm{H}_{41} \mathrm{NO}_{6} \cdot 2 \mathrm{H}_{2} \mathrm{O}: \mathrm{C}$, 67.22; H, 7.93; N, 2.45. Found: C, 67.58; H, 8.09; N, 2.80. ES-MS: $[\mathrm{M}]^{+}=336.4 ;[\mathrm{M}]^{-}=199.6$.

Berberine bis(trifluoromethane)sulfonamide $\left(\right.$ Ber $\left.^{+} \mathrm{NTf}_{2}{ }^{-}\right)$. Yield: $69 \% .{ }^{1} \mathrm{H}$ NMR $\left(\mathrm{CD}_{3} \mathrm{OD}\right): \delta$ $\mathrm{ppm}=3.25(\mathrm{t}, J=6.0 \mathrm{~Hz}, 2 \mathrm{H}, \mathrm{H} 5), 4.11\left(\mathrm{~s}, 3 \mathrm{H}, \mathrm{C} 10-\mathrm{OCH}_{3}\right), 4.20\left(\mathrm{~s}, 3 \mathrm{H}, \mathrm{C} 9-\mathrm{OCH}_{3}\right), 4.92(\mathrm{t}, J=6.0$ $\mathrm{Hz}, 2 \mathrm{H}, \mathrm{H} 6), 6.11$ (s, 2H, O-CH ${ }_{2}-\mathrm{O}$ ), 6.96 (s, 1H, H4), 7.66 (s, 1H, H1), 7.99 (d, J= 9.0 Hz, 1H, H12), 8.12 (d, $J=9.0 \mathrm{~Hz}, 1 \mathrm{H}, \mathrm{H} 11), 8.70$ (s, $1 \mathrm{H}, \mathrm{H} 13), 9.76$ (s, $1 \mathrm{H}, \mathrm{H} 8) .{ }^{19} \mathrm{~F} \mathrm{NMR}\left(\mathrm{CD}_{3} \mathrm{OD}\right): \delta \mathrm{ppm}=-80.68$. (s, $\mathrm{CF}_{3}$ ). Anal. calc. for $\mathrm{C}_{22} \mathrm{H}_{18} \mathrm{~F}_{6} \mathrm{~N}_{2} \mathrm{O}_{8} \mathrm{~S}_{2}$ : C, 42.86; H, 2.94; N, 4.54. Found: C, 42.34; H, 2.70; N, 4.36. ES-MS: $[\mathrm{M}]^{+}=336.1 ;[\mathrm{M}]^{-}=279.9$.

\section{Crystallographic data}

Crystal data were collected at low temperature (193K) on a Bruker-AXS SMART APEX II diffractometer $\left(\mathrm{Ber}^{+} \mathrm{Lau}^{-}\right)$and on a Bruker AXS Quazar APEX II diffractometer (Ber ${ }^{+} \mathrm{AOT}^{-}, \mathrm{Ber}^{+} \mathrm{Tos}^{-}$, 
Ber ${ }^{+} \mathrm{TPB}^{-}, \mathrm{Ber}^{+} \mathrm{DS}-\mathrm{Ber}^{+} \mathrm{NTf}_{2}^{-}$) using a $30 \mathrm{~W}$ air-cooled microfocus source (ImS) with focusing multilayer optics using MoK $\alpha$ radiation (wavelength $=0.71073 \AA$ ). Phi- and omega-scans were used. The structures were solved by direct methods (ShelXS-97) or using an intrinsic phasing method (ShelXT) ${ }^{51,52}$ All non-hydrogen atoms were refined anisotropically using the least-square method on $F^{2} .52$ ORTEP molecular views are given in Figures S4 to S8 (Supplementary Information). Crystallographic data are given in Table 4. CCDC supplementary crystallographic data for the structures can be obtained free of charge via www.ccdc.cam.ac.uk/conts/retrieving.html (or for the CCDC, 12 Union Road, Cambridge CB2 1EZ, UK; fax: +441223 336033; e-mail: deposit@ccdc.cam.ac.uk).

\section{Apparatus and methods}

Mass and NMR spectra were obtained in the relevant 'Services communs de l'Institut de Chimie de Toulouse, Université Toulouse III Paul-Sabatier'. Protons were numbered according to literature data (see Figure 1). ${ }^{29}$ Mass spectra were recorded using a Waters LCT and a Waters Q TOF premier spectrometer using the electrospray ionization technique. The ${ }^{1} \mathrm{H}$ NMR and ${ }^{19} \mathrm{~F}$ NMR spectra were recorded on a Bruker AC300 spectrometer operating at 300.13 and $282.18 \mathrm{MHz}$, respectively. The microanalyses were performed with an EA1112 elemental analyzer from CE instruments in the 'Service inter-universitaire de microanalyses de l'ENCIACET' and a Perkin Elmer 2400 elemental analyzer in the 'Service d'Analyse Chimique du Laboratoire de Chimie de Coordination de Toulouse'.

For solid state measurements, the diffuse reflectance spectra of the powders were measured with a Perkin-Elmer 860 Spectrophotometer equipped with a $15 \mathrm{~cm}$ diameter integrating sphere bearing the holder in the bottom horizontal position. They were recorded at room temperature in steps of $1 \mathrm{~nm}$, with a bandwidth of $2 \mathrm{~nm}$. The instrument was calibrated with a certified Spectralon white standard (Labsphere, North Sutton, USA). The Kubelka-Munk model described light penetration in homogeneous and optically thick media with only two parameters: an absorption coefficient $K$ and anisotropic scattering coefficient $S$ (both in $\mathrm{cm}^{-1}$ ). ${ }^{53}$ This model allowed us to deduce that there was a simple relationship between the reflectance at "infinite thickness" $R_{\infty}$ and the absorption and scattering coefficients: $\mathrm{F}\left(R_{\infty}\right)=\left(1-R_{\infty}\right) 2 / 2 R_{\infty}=K / S$. For materials where the dye did not aggregate and did not fluoresce, the law could be applied, so that $K$ was the dye absorptivity $\left(\varepsilon\right.$ in $\left.\mathrm{M}^{-1} \mathrm{~cm}^{-1}\right)$ scaled by the effective concentration $C(\mathrm{M})$. The $K / S$ ratio was then equal to $K / S=(\varepsilon \times C) / S$. Solid state photoluminescence quantum yields were recorded on a SAFAS Xenius spectrofluorometer equipped with a $\mathrm{BaSO}_{4}$ integrating sphere and a Hamamatsu R2658 detector. Solid samples were deposited on a metal support and luminescence spectra were corrected. The absolute photoluminescence quantum yield values $\left(\Phi_{P}\right)$ were determined by a method based on the one developed by de Mello et al. ${ }^{54}$ The excitation source was scanned in order to evaluate the reflected light for the empty sphere $\left(L_{a}\right)$, the samples facing the source light $\left(L_{c}\right)$ and the sample out of the irradiation beam $\left(L_{b}\right)$. The fluorescence spectra were recorded with the sample facing the source light $\left(E_{c}\right)$ and out from the direct irradiation $\left(E_{b}\right)$. The PM voltage was adapted to the measurement of reflected light and emission spectra, respectively, and proper correction was applied to take into account the voltage difference. The $\Phi_{P}$ values were then calculated using the formula:

$$
\Phi_{P}=E_{c}-(1-\alpha) E_{b} / L_{a} \alpha
$$

with $\alpha=1-L_{c} / L_{b}$. The error was estimated to be about $20 \%$. 


\begin{tabular}{|c|c|c|c|c|c|c|}
\hline Compound & $\mathrm{Ber}^{+} \mathrm{AOT}^{-}$ & $\mathrm{Ber}^{+} \mathrm{Tos}^{-}$ & $\mathrm{Ber}^{+} \mathrm{TPB}^{-}$ & $\mathrm{Ber}^{+} \mathrm{Lau}^{-}$ & $\mathrm{Ber}^{+} \mathrm{DS}^{-}$ & $\mathrm{Ber}^{+} \mathrm{NTf}_{2}^{-}$ \\
\hline $\begin{array}{l}\text { Empirical formula } \\
\text { Formula weight }\end{array}$ & $\begin{array}{l}\mathrm{C}_{20} \mathrm{H}_{18} \mathrm{NO}_{4}^{+} . \\
\mathrm{C}_{20} \mathrm{H}_{37} \mathrm{O}_{7} \mathrm{~S}^{-} \\
757.91\end{array}$ & $\begin{array}{l}\mathrm{C}_{20} \mathrm{H}_{18} \mathrm{NO}_{4}^{+} . \\
\mathrm{C}_{7} \mathrm{H}_{7} \mathrm{O}_{3} \mathrm{~S}^{-} \cdot \mathrm{CH}_{4} \mathrm{O} \\
539.58\end{array}$ & $\begin{array}{l}\mathrm{C}_{20} \mathrm{H}_{18} \mathrm{NO}_{4}{ }^{+} \\
. \mathrm{C}_{24} \mathrm{H}_{20} \mathrm{~B}^{-} \\
655.56\end{array}$ & $\begin{array}{l}\mathrm{C}_{20} \mathrm{H}_{18} \mathrm{NO}_{4}{ }^{+} . \\
\mathrm{C}_{12} \mathrm{H}_{23} \mathrm{O}_{2}^{-} .4 \mathrm{H}_{2} \mathrm{O} \\
607.72\end{array}$ & $\begin{array}{l}\mathrm{C}_{20} \mathrm{H}_{18} \mathrm{NO}_{4}{ }^{+} . \\
\mathrm{C}_{12} \mathrm{H}_{25} \mathrm{SO}_{4}^{-} .1 / 2 \mathrm{H}_{2} \mathrm{O} \\
610.74\end{array}$ & $\begin{array}{l}\mathrm{C}_{20} \mathrm{H}_{18} \mathrm{NO}_{4}{ }^{+} . \\
\mathrm{C}_{2} \mathrm{~F}_{6} \mathrm{NO}_{4} \mathrm{~S}_{2}^{-} \\
616.50\end{array}$ \\
\hline Crystal system & Triclinic & Triclinic & Monoclinic & Monoclinic & Monoclinic & Triclinic \\
\hline Space group & $P 1$ & $P 1$ & $P 2{ }_{1} / c$ & $P 2{ }_{1} / n$ & $\mathrm{C} 2 / \mathrm{c}$ & $P 1$ \\
\hline Unit cell dimensions & & & & & & \\
\hline$a(\AA)$ & $8.296(3)$ & $7.1974(5)$ & $13.2946(12)$ & $11.3010(5)$ & $43.206(9)$ & $7.9779(4)$ \\
\hline$b(\stackrel{\mathrm{A}}{)})$ & $10.559(4)$ & $12.5766(10)$ & $11.5487(10)$ & $6.6661(3)$ & $7.0750(16)$ & $14.2778(7)$ \\
\hline$c(\AA)$ & $22.575(8)$ & $14.1544(11)$ & $22.664(2)$ & $43.6661(19)$ & $22.126(5)$ & $21.8106(11)$ \\
\hline$\alpha\left(^{\circ}\right)$ & $87.070(18)$ & $78.981(5)$ & 90 & 90 & 90 & $86.203(2)$ \\
\hline$\beta\left(^{\circ}\right)$ & $89.387(16)$ & $87.111(5)$ & $101.108(5)$ & $96.490(3)$ & $111.687(12)$ & $80.015(2)$ \\
\hline$\gamma\left(\left(^{\circ}\right)\right.$ & $82.151(19)$ & $83.558(5)$ & 90 & 90 & 90 & $89.901(2)$ \\
\hline Volume $\left(\AA^{3}\right)$ & $1956.4(12)$ & $1249.13(16)$ & $3414.5(5)$ & $3268.4(3)$ & $6285(2)$ & $2441.3(2)$ \\
\hline $\mathrm{Z}$ & 2 & 2 & 4 & 4 & 8 & 4 \\
\hline Crystal size $\left(\mathrm{mm}^{3}\right)$ & $0.16 \times 0.04 \times 0.01$ & $0.60 \times 0.06 \times 0.06$ & $0.20 \times 0.15 \times 0.12$ & $0.40 \times 0.05 \times 0.02$ & $0.80 \times 0.06 \times 0.01$ & $0.60 \times 0.40 \times 0.30$ \\
\hline Reflections collected & 36770 & 20682 & 66154 & 41622 & 27802 & 35296 \\
\hline Independent reflections & 6363 & 4692 & 8426 & 6626 & 5285 & 10615 \\
\hline $\mathrm{R}_{\text {int }}$ & 0.2093 & 0.0507 & 0.0616 & 0.1974 & 0.1333 & 0.0208 \\
\hline Parameters/Restraints & $626 / 456$ & $348 / 0$ & $486 / 85$ & $514 / 384$ & $502 / 433$ & $725 / 0$ \\
\hline Final $R_{1}$ index $\mathrm{I}>2 \sigma(\mathrm{I})$ & 0.0851 & 0.0449 & 0.0492 & 0.0565 & 0.0910 & 0.0417 \\
\hline$w R 2$ all data & 0.2592 & 0.1204 & 0.1235 & 0.1330 & 0.2611 & 0.1160 \\
\hline $\begin{array}{l}\text { Largest diff. peak and hole } \\
\left(\mathrm{e} . \AA^{-3}\right)\end{array}$ & 0.425 and -0.524 & 0.329 and -0.364 & 0.237 and -0.311 & 0.177 and -0.192 & 0.398 and -0.283 & 0.461 and -0.568 \\
\hline $\mathrm{CCDC}$ & CCDC1481156 & CCDC1481157 & CCDC1481158 & CCDC1481159 & CCDC1481160 & CCDC1481161 \\
\hline
\end{tabular}

Table 4. Crystallographic data 
To measure the apparent octanol-water partition coefficient $\log \mathrm{P}_{a p p}$, each berberine salt was carefully dissolved in water-saturated $n$-octanol, the solutions were filtered and the initial absorbance $A_{i}$ was measured. Concentrations were between $1.7 \times 10^{-5} \mathrm{M}$ and $2.2 \times 10^{-4} \mathrm{M}$ according to the salt. For most of the salts, a given volume of octanol solution was then added to the same volume of water. For Ber $^{+} \mathrm{SD}^{-}$and Ber $^{+} \mathrm{AOT}^{-}$, the volume of water $V_{w}$ was ten times that of octanol $V_{o}$. After $24 \mathrm{~h}$ stirring in the dark at room temperature, the absorbance of the organic phase at equilibrium $A_{e q}$ was measured. The partition coefficient value $\log P_{a p p}$ was calculated as: $\log P_{a p p}=\log \left(\left(A_{e q} /\left[A_{i}-A_{e q}\right]\right) . V_{w} / V_{o}\right)$.

The size and shape of micro/nanoparticles were observed with Zeiss Axioskop and Leitz Laborlux D fluorescence microscopes equipped with an Andor Luca camera. The excitation wavelength was 435-450 nm and the emission wavelength was set at around 500-530 nm, using suitable filters.

\section{ACKNOWLEDGMENTS}

The authors are very grateful to EuroNanoMed ERA-NET JTC2011 (FONDIAG project) for financial support. We are indebted to Dr. Christophe Leroux (Laboratoire GET, Toulouse) for the gift of lithium bis(trifluoromethane)sulfonamide and to Dr. Nadine Leygues (SPCMIB, Toulouse) for NMR spectra. We also thank Mrs. Roxanne Castanet (CNRS-DR14) for allowing the correction of the English and Mrs. Pauline Haas Hammel for the quality of her work, unfortunately ruined in the revised version.

\section{REFERENCES}

1 A. Patra, Ch. G. Chandaluri and T. P. Radhakrishnan, Nanoscale 2012, 4, 343-359.

2 Y. S. Zhao, H. Fu, A. Peng, Y. Ma, Q. Liao and J. Yao, Acc. Chem. Res. 2010, 43, 409-418.

3 R. Jagannathan, G. Irvin, T. Blanton and S. Jagannathan, Adv. Funct. Mater. 2006, 16, 747-753.

4 S. Fery-Forgues, Nanoscale 2013, 5, 8428-8442.

5 A. S. Klymchenko, J. Nanosci. Lett. 2013, 3, 21.

6 Y. Hong, J. W. Y. Lam and B. Z. Tang, Chem. Soc. Rev. 2011, 40, 5361-5388.

7 H. Yao, in Springer Series on Fluorescence Methods and Applications: Advanced fluorescence reporters in chemistry and biology II. Vol. 9 (Eds: O. S. Wolfbeis, A. P. Demchenko), Springer Berlin, Heidelberg, 2010, pp. 285-304.

8 B. M. Krasovitskii and B. M. Bolotin (Eds.), Organic Luminescent Materials, VCH, Weinheim, 2002.

9 J. B. Birks (Ed.), Photophysics of Aromatic Molecules, Wiley, London, 1970.

10 J. Cornil, D. Beljonne, D. A. Dos Santos, J. P. Calbert, Z. Shuai and J. L. Brédas, C. R. Acad. Sci. Paris 2000, Series IV, 403-408.

11 J. Schill, A. P. H. J. Schenning and L. Brunsveld, Macromol. Rapid Commun. 2015, 36, 1306-1321.

12 H. Langhals, O. Krotz, K. Polborn and P. Mayer, Angew. Chem. Int. Ed. 2005, 44, 2427-2428.

13 J. N. Moorthy, P. Natarajan, P. Venkatakrishnan, D. F. Huang and T. J. Chow, Org. Lett. 2007, 9, 5215-5218. 14 S. Fery-Forgues, in Aggregation-Induced Emission (Eds: A. Qin and B. Z. Tang), John Wiley \& Sons Ltd., Singapore, 2014, pp. 104-124.

15 H. Yao, M. Yamashita and K. Kimura, Langmuir, 2009, 25, 1131-1137.

16 T. Enseki and H. Yao, Chem. Lett. 2012, 41, 1119-1121.

17 J.-F. Lamère, N. Saffon, I. Dos Santos and S. Fery-Forgues, Langmuir, 2010, 26, 10210-10217.

18 J. Chahine, N. Saffon, M. Cantuel and S. Fery-Forgues, Langmuir, 2011, 27, 2844-2853.

19 S. Das, D. Bwambok, B. El-Zahab, J. Monk, S. L. de Rooy, S. Challa, M. Li, F. R. Hung, G. A. Baker and I. M. Warner, Langmuir, 2010, 26, 12867-12876. 
20 S. L. De Rooy, S. Das, M. Li, B. El-Zahab, A. Jordan, R. Lodes, A. Weber, L. Chandler, G. A. Baker and I. M. Warner, J. Phys. Chem. C, 2012, 116, 8251-8260.

21 A. N. Jordan, S. Das, N. Siraj, S. L. De Rooy, M. Li, B. El-Zahab, L. Chandler, G. A. Baker and I. M. Warner, Nanoscale 2012, 4, 5031-5038.

22 I. Shulov, S. Oncul, A. Reisch, Y. Arntz, M. Collot, Y. Mely and A. S. Klymchenko, Nanoscale 2015, 7, 18198-18210.

23 M. Soulié, C. Frongia, V. Lobjois and S. Fery-Forgues, RSC Advances, 2015, 5, 1181-1190.

24 P. K. S. Magut, S. Das, V. E. Fernand, J. Losso, K. McDonough, B. M. Naylor, S. Aggarwal and I. M. Warner, J. Am. Chem. Soc. 2013, 135, 15873-15879.

25 T. Hinoue, Y. Shigenoi, M. Sugino, Y. Mizobe, I. Hisaki, M. Miyata and N. Tohnai, Chem. Eur. J., 2012, 18, 4634-4643.

26 M. S. Arayne, N. Sultana and S. S. Bahadur, Pak. J. Pharm. Sci., 2007, 20, 83-92.

27 J. S. Modica-Napolitano and J. R. Aprille, Adv. Drug. Deliv. Rev., 2001, 49, 63-70 and references therein.

28 D. S. Bhakuni and S. Jain, in The Alkaloids: Chemistry and Pharmacology, Vol. 28 (Ed.: A. Brossi), Academic Press, New York, 1986, pp. 95-181.

29 L. Grycová, J. Dostál and R. Marek, Phytochemistry, 2007, 68, 150-175.

30 B. M. Kariuki and W. Jones, Acta Cryst. 1995, C51, 1234-1240.

31 H. H. Y. Tong, A. S. F. Chow, H. M. Chan, A. H. L. Chow, Y. K. Y. Wan, I. D. Williams, F. L. Y. Shek and C. K. Chan, J. Pharm. Sci., 2010, 99, 1942-1954.

32 J. Marek, D. Hulová, J. Dostál and R. Marek, Acta Cryst. C, 2003, 59, o583-o585.

33 S. Man, M. Potáček, M. Nečas, Z. Žák and J. Dostál, Molecules, 2001, 6, 433-441.

34 B. E. A. Abadi, D. S. Moss and R. A. Palmer, J. Cryst. Spectrosc. Res., 1984, 14, $269-281$.

35 M. S. Díaz, M. L. Freile and M. I. Gutiérrez, Photochem. Photobiol. Sci. 2009, 8, 970-974.

36 J. J. Inbaraj, B. M. Kukielczak, P. Bilski, S. L. Sandvik and C. F. Chignell, Chem. Res. Toxicol. 2001, 14, 1529-1534.

37 M. O. Iwunze, Monatsh. Chem. 2000, 131, 429-435.

38 A. Delgado-Camón, R. Garriga, E. Mateos, V. L. Cebolla, J. Galbàn, L. Membrado, S. de Marcos and E. M. Gálvez, Chem. Phys. Lett. 2011, 501, 547-553.

39 M. Megyesi and L. Biczók, Chem. Phys. Lett., 2006, 424, 71-76.

40 C. R. Gade and N. K. Sharma, RSC Adv., 2014, 4, 39337-39342.

41 N. Siraj, F. Hasan, S. Das, L. W. Kiruri, K. E. Steege Gall, G. A. Baker and I. M. Warner, J. Phys. Chem. C 2014, 118, 2312-2320.

42 R. Katoh, K. Suzuki, A. Furube, M. Kotani and K. Tokumaru, J. Phys. Chem. C 2009,113, 2961-2965.

43 C. Yi, C. Blum, S. X. Liu, Y. F. Ran, G. Frei, A. Neels, H. Stoeckli-Evans, G. Calzaferri, S. Leutwyler and S. Decurtins, Crystal Growth Des. 2008, 8, 3004-3009.

44 A. Andrés, M. Rosés, C. Ràfols, E. Bosch, S. Espinosa, V. Segarra and J. M. Huerta, Eur. J. Pharm. Sci.

2015, 76, 181-191.

45 A. Leo, C. Hansch and D. Elkins, Chem. Rev. 1971, 71, 525-615.

46 H. Nakanishi and H. Oikawa, in Single Organic Nanoparticles (Eds.: H. Masuhara, H. Nakanishi and K. Sasaki), Springer-Verlag, Berlin, 2003, Chapter 2, pp 17-31.

47 K. Khemakhem, M. Soulié, R. Brousses, H. Ammar, S. Abid and S. Fery-Forgues, Chem. Eur. J. 2015, 21, 7927- 7937.

48 N. Abid-Jarraya, H. Turki-Guermazi, K. Khemakhem, S. Abid, N. Saffon and S. Fery-Forgues, Dyes Pigm. 2014, 101, 164-171.

49 S. Fery-Forgues and C. Fournier-Noël, in Nanofibers (Ed.: A. Kumar) InTech, 2010, pp. 383-404.

50 H. Fu, D. Xiao, J. Yao and G. Yang, Angew. Chem. Int. Ed. 2003, 42, 2883-2886.

51 G. M. Sheldrick, Acta Cryst. A 2015, 71, 3-8.

52 G. M. Sheldrick, Acta Cryst. C 2015, 71, 3-8.

53 P. Kubelka and P. Z. Munk, Z. für Tech. Phys. 1931, 12, 593-601.

54 J. C. De Mello, H. F. Wittmann and R. H. Friend, Adv. Mater. 1997, 9, 230-232. 